\title{
Plating versus intramedullary fixation for mid-shaft clavicle fractures: A systemic review and meta-analysis
}

Yan Gao, Wei Chen, Yue-Jv Liu, Xu Li, Hai-Li Wang, Zhao-yu Chen

Background Plate fixation and intramedullary fixation are the most commonly used surgical treatment options for mid-shaft clavicle fractures; the latter method has demonstrated better performance in some studies. Objectives Our aim was to critically review and summarize the literature comparing the outcomes of mid-shaft clavicle fracture treatment with plate fixation or intramedullary fixation to identify the better approach.

Search Methods Potential academic articles were identified from the Cochrane Library, MEDLINE (1966-2015.5), PubMed (1966-2015.5), EMBASE (1980-2015.5) and ScienceDirect (1966-2015.5). Gray studies were identified from the references of the included literature.

Selection Criteria Randomized controlled trials (RCTs) and non-RCTs comparing plate fixation and intramedullary fixation for mid-shaft clavicle fracture were included. Data Collection and Analysis Two reviewers performed independent data abstraction. The $I^{2}$ statistic was used to assess heterogeneity. A fixed- or random-effects model was used for the meta-analysis. Results. Six RCTs and nine non-RCTs were retrieved, including 513 patients in the intramedullary fixation group and 521 patients in the plating group. No significant differences in terms of the union rate and shoulder function were found between the groups. Patients in the intramedullary fixation group had a shorter operative time, less blood loss, smaller wound size, and shorter union time than those in the plating group. With respect to complications, significant differences were identified for all complications and major complications (wound infection, nonunion, implant failures, transient brachial plexopathy, and pain after 6 months). Similar secondary complications (symptomatic hardware, hardware irritation, prominence, numbness, hypertrophic callus) were observed in both groups. Conclusions Intramedullary fixation may be superior to plate fixation in the treatment of mid-shaft clavicle fractures, with similar performance in terms of the union rate and shoulder function, better operative parameters and fewer complications. 
1 Title: Plating versus intramedullary fixation for mid-shaft clavicle fractures: A systemic

2 review and meta-analysis

3

4 Authors: Yan Gao ${ }^{1}$ M.D., Ph.D, Wei Chen" ${ }^{2,3}$ M.D., Ph.D., Yue-Jv Liu' ${ }^{2,3}$ M.D., Ph.D., Xu Li ${ }^{2,3}$

5 MD, Hai-Li Wang ${ }^{2,3}$ M.D., Ph.D., Zhao-Yu Chen ${ }^{2,3,4}$ M.D.

6

7 1: Department of Endocrinology, The Second Hospital of Hebei Medical University,

8 Shijiazhuang, Hebei Province, People's Republic of China

Address: No. 215, Heping Xi Road, Shijiazhuang, Hebei Province, People's Republic of

2: Department of Orthopedics, The Third Hospital of Hebei Medical University, Shijiazhuang, Hebei Province, People's Republic of China 050051 100044

3: Key Laboratory of Orthopedic Biomechanics of Hebei Province, The Third Hospital of Hebei Medical University, Shijiazhuang, Hebei Province, People’s Republic of China

Address: No. 139, Ziqiang Road, Shijiazhuang, Hebei Province, People's Republic of China, 050051

4: Arthritis Clinic and Research Center, Peking University People's Hospital, Beijing, People's Republic of China

Address: No. 11, Xzhimen Street, Xicheng District, Beijing, People's Republic of China,

*Corresponding author: Zhao-Yu Chen, M.D., Ph.D. 
Email: hbchenzhaoyu@163.com

Tel: +86-18633019868

Department of Orthopedics, The Third Hospital of Hebei Medical University, Shijiazhuang, Hebei Province, People's Republic of China

Address: No. 139, Ziqiang Road, Shijiazhuang, Hebei Province, People's Republic of China, 050051

Key Laboratory of Orthopedic Biomechanics of Hebei Province, The Third Hospital of Hebei Medical University, Shijiazhuang, Hebei Province, People's Republic of China Address: No. 139, Ziqiang Road, Shijiazhuang, Hebei Province, People's Republic of China, 050051

Arthritis Clinic and Research Center, Peking University People's Hospital, Beijing, People's

Republic of China

Address: No. 11, Xzhimen Street, Xicheng District, Beijing, People's Republic of China, 100044

Yan Gao M.D., Ph.D., Email: hbsjzgaoyan@163.com

Wei Chen M.D., Ph.D., Email: hbsjzchenwei@163.com

Yue-Jv Liu M.D., Ph.D., Email: dagangchenhui@163.com

Xu Li M.D., Email: hbsjzlixu@,163.com

Hai-Li Wang M.D., Ph.D., Email: hbsjzwanghaili@163.com

Zhao-Yu Chen M.D., Email: hbchenzhaoyu@163.com

\section{Acknowledgements: None.}

\section{Conflict of interest}


55

56

57

58

59

60

61

62

63

64

65

66

67

All authors declare that they have no conflicts of interest.

\section{Plating versus intramedullary fixation for mid-shaft clavicle fractures: A}

\section{systemic review and meta-analysis}

\section{Abstract}

Background Plate fixation and intramedullary fixation are the most commonly used surgical treatment options for mid-shaft clavicle fractures; the latter method has demonstrated better performance in some studies.

Objectives Our aim was to critically review and summarize the literature comparing the outcomes of mid-shaft clavicle fracture treatment with plate fixation or intramedullary fixation to identify the better approach.

Search Methods Potential academic articles were identified from the Cochrane Library, MEDLINE (1966-2015.5), PubMed (1966-2015.5), EMBASE (1980-2015.5) and ScienceDirect (1966-2015.5). Gray studies were identified from the references of the included literature.

Selection Criteria Randomized controlled trials (RCTs) and non-RCTs comparing plate fixation and intramedullary fixation for mid-shaft clavicle fracture were included.

Data Collection and Analysis Two reviewers performed independent data abstraction. The $\mathrm{I}^{2}$ statistic was used to assess heterogeneity. A fixed- or random-effects model was used for the meta-analysis.

Results. Six RCTs and nine non-RCTs were retrieved, including 513 patients in the intramedullary fixation group and 521 patients in the plating group. No significant differences in terms of the union rate and shoulder function were found between the groups. Patients in the 
80

intramedullary fixation group had a shorter operative time, less blood loss, smaller wound size, and shorter union time than those in the plating group. With respect to complications, significant differences were identified for all complications and major complications (wound infection, nonunion, implant failures, transient brachial plexopathy, and pain after 6 months). Similar secondary complications (symptomatic hardware, hardware irritation, prominence, numbness, hypertrophic callus) were observed in both groups.

Conclusions Intramedullary fixation may be superior to plate fixation in the treatment of midshaft clavicle fractures, with similar performance in terms of the union rate and shoulder function, better operative parameters and fewer complications.

Key Words Intramedullary fixation; plating fixation; mid-shaft clavicle fractures; metaanalysis

\section{Introduction}

Clavicular fractures are common, comprising $2.6-10 \%$ of all fractures (O'Neill et al., 2011), and approximately $80 \%$ of clavicle fractures involve the middle shaft. The majority of these clavicle fractures occur in patients who are younger than 40 or older than 70 years (Kim and McKee, 2008). Non-operative therapy can be successful, with high union rates that may be maintained for decades. Although only $7 \%$ of patients with clavicle fractures developed nonunion after conservative treatment, $46 \%$ of patients in the study of Nowak et al. had persistent symptoms 10 years after the injury (Nowak et al., 2004). Based on recent studies, there has been a trend toward the surgical treatment of clavicle fractures.

More than $50 \%$ of clavicle fractures are displaced (Postacchini et al., 2002). Displaced fractures carry a risk of malunion or nonunion, both of which result in non-satisfactory function. According to Zlowodzki et al., the overall nonunion rate for clavicle fractures was 5.9\%, whereas the rate for displaced fractures was $15.1 \%$ (Zlowodzki et al., 2005). Recent prospective randomized studies have reported superior functional results with intramedullary nailing (Smekal 
et al., 2009) or plating (Society, 2007) compared with conservative treatment. Moreover, a recent meta-analysis revealed a significantly lower nonunion rate after surgical treatment (Zlowodzki et al., 2005). Early surgical intervention has therefore been suggested to improve outcomes and to decrease the rates of nonunion and symptomatic malunion in mid-shaft clavicle fractures with the following features: open injury, shortening or displacement $>20 \mathrm{~mm}$, multiple trauma, floating shoulder, or cosmetic concerns (Society, 2007; Hill et al., 1997).

Plate fixation is the standard surgical therapy for mid-shaft clavicular fractures (Ali and Lucas, 1978). A $2.2 \%$ nonunion rate was reported in a review synthesizing the results of earlier studies on displaced clavicular fractures treated by plate fixation (Zlowodzki et al., 2005). However, clavicular plates require larger skin incisions and extensive soft tissue stripping, which increase the risk for nonunion and wound infection. Moreover, clavicle re-fracture occurred after plate removal in 0 to $8 \%$ of the patients (Bostman et al., 1997; Poigenfurst et al., 1992). The Knowles pin, the Rockwood pin, and the titanium elastic nail (TEN) have been developed to minimize postoperative complications (Jubel et al., 2003). From a biomechanical perspective, intramedullary implant positioning is ideal (Mueller et al., 2008). With the advantages of intact hematoma maintenance, less soft tissue dissection and periosteal stripping, all of which can accelerate fracture healing, intramedullary fixation has been gaining attention for its superior performance. Unfortunately, hardware migration (including medial migration and lateral perforation) has been a problem with intramedullary fixation. The rate of TEN migration ranges between $4.5 \%$ and $26.6 \%$ in the literature (Meier et al., 2006; Kettler et al., 2007). Overall, different complication rates were reported for these two fixation methods, but no significant differences were noted for most of them. Significantly more instances of symptomatic hardware, infection, nonunion, wound dehiscence, and refractures were reported with plate fixation than with intramedullary fixation in studies (Lee et al., 2007; Saha et al., 2014; Narsaria et al. 2014). Furthermore, mobilization after intramedullary fixation requires more attention because conduction stabilization is weaker with intramedullary fixation than with plate fixation (Frigg et al., 2009). 
Several meta-analyses comparing plate and intramedullary fixation were published from 2011 to 2015 (Duan et al., 2011; Houwert et al., 2012; Barlow et al., 2013; Zhu et al., 2015). However, the studies included were not exactly comparable, and fewer than 5 RCTs or quasi-RCT (qRCT) studies were included. Here, we review and summarize all of the RCTs and non-RCTs comparing plate and intramedullary fixation in the hopes of presenting useful data to identify the better treatment choice and to confirm the findings of these studies.

\section{Material and Methods}

\section{Inclusion and Exclusion Criteria}

Trials with the following characteristics were included: (1) RCTs or non-RCTs, (2) patients with midshaft clavicle fractures from trauma and without pathological fractures, (3) comparison of the results of intramedullary and plating fixation, and (4) full-text articles. We excluded articles that were duplicate reports of earlier trials or post-hoc analyses of RCT data and articles without an available full-text version. Studies including patients suffering multiple traumas were also excluded.

\section{Search Strategy}

Electronic searches of the Cochrane Library, MEDLINE (1966-2015.5), PubMed (19662015.5), EMBASE (1980-2015.5) and ScienceDirect (1966-2015.5) as well as other Internet databases were performed to identify trials, according to the Cochrane Collaboration guidelines. We used the following search terms and different combinations of Medical Subject Heading (MeSH) terms and textual words: "clavicle or clavicular", "fracture", "midshaft or mid-shaft", "intramedullary", "plate, plates or plating". Manual searches, including those of the reference lists of all included studies, were used to identify trials that the electronic search may have failed to identify. Two reviewers (Yan Gao and Zhao-Yu Chen) independently assessed the titles and abstracts of all of the reports identified by the electronic and manual searches. There was no restriction on language. When inclusion was unclear based on the abstracts alone, the full-text 
161 162

\section{3}

articles were retrieved. Any disagreements were resolved through discussion.

\section{Assessment of Methodological Quality}

Quality assessment of RCTs and non-RCTs was conducted according to a modification of the generic evaluation tool used by the Cochrane Bone, Joint and Muscle Trauma Group (Handoll et al., 2008) or the index for non-randomized studies form (Slim et al., 2003). The methodological quality of each trial was scored from 0 to 24 . Disagreements were resolved by consensus or by consultation with the senior reviewer (Wei Chen).

\section{Data Extraction}

Two authors (Yan Gao and Yue-Jv Liu) independently extracted data from the included articles. Information regarding the study design, patient demographics, inclusion and exclusion criteria, interventions, outcomes, follow-up duration and rate of loss to follow-up for each treatment group were extracted. When continuous outcomes were published as the median and range in the original papers, the mean value and standard deviation were estimated using the formula provided by Hozo et al. (2005) Data were managed using Review Manager (RevMan) 5.1 software (The Nordic Cochrane Centre, The Cochrane Collaboration, Copenhagen, Denmark). We attempted to contact authors for supplementary information when the reported data were inadequate.

\section{Data Analysis and Statistical Methods}

The meta-analysis was conducted using RevMan 5.1 for Windows (Cochrane Collaboration, Oxford, United Kingdom). Statistical heterogeneity was assessed for each study, using a standard Chi square test, with significance set at a $\mathrm{P}$ value of 0.1 , which was measured by the $\mathrm{I}^{2}$ statistic. When $\mathrm{I}^{2}>50 \%, \mathrm{P}<0.1$ was considered to be significant heterogeneity (Higgins et al., 2003). Therefore, a random-effects model was applied for data analysis (Lau et al., 1997). A fixedeffects model was used when no significant heterogeneity was found. In cases of significant 
heterogeneity, subgroup analysis was performed to investigate sources. The odds ratio (OR) and 95\% confidence interval (CI) were calculated for dichotomous outcomes, whereas the mean difference (MD) and 95\% CI were used for continuous outcomes.

\section{Results}

\section{Literature search}

Figure 1 shows a flow chart of the study selection and inclusion process. The search strategy identified 194 citations; of these, six RCTs and nine non-RCTs met the pre-defined inclusion criteria for data extraction and meta-analysis.

\section{Study characteristics}

Individual patient data were obtained from these articles. Population information is summarized in Table 1. These studies included 513 patients in the intramedullary fixation (IF) group and 521 patients in the plate fixation $(\mathrm{PF})$ group, excluding those lost to follow up. Between-group differences in the baseline characteristics were not found. The quality assessment scores of the studies ranged from 17 to 20 .

\section{Risk of bias assessment}

For the RCTs, unclear blindness was the major problem (details are provided in Table 2). For the nine non-RCTs, no prospective calculation of the sample size was described. Moreover, no information regarding the unbiased assessment of study endpoints was available. Only five studies reported the relevant information regarding the prospective collection of data. The methodological quality assessment is illustrated in Figure 2.

\section{Meta-analysis outcomes}

Blood Loss 
214

215

216

217

218

219

220

221

222

223

224

225

226

227

228

229

230

231

232

233

234

235

236

237

238

239

240

Blood loss was reported in five studies (Liu et al., 2010; Chen et al., 2012; Tarng et al., 2012; Saha et al., 2014; Narsaria et al., 2014), including 200 patients in the IF group and 244 patients in the PF group. The mean blood loss and standard deviation were estimated from the study of Tarng et al. (2012). Greater blood loss was observed in the PF group than in the IF group (MD = $-64.14 ; 95 \%$ CI: -66.88 to $-61.40 ; \mathrm{P}<0.001$; Figure 3$)$.

\section{Operative Time}

Operative time was reported in seven studies (Lee et al., 2008; Liu et al., 2010; Assobhi, 2011; Chen et al., 2012; Tarng et al., 2012; Narsaria et al., 2014; Saha et al., 2014), including 275 patients in the IF group and 295 patients in the PF group. The mean operative time and standard deviation were estimated from the studies of Tarng et al. (2012) and Narsaria N et al. (2014) The operative time was shorter in the IF group than in the PF group (MD $=-22.30 ; 95 \% \mathrm{CI}:-30.42$ to -14.18; $\mathrm{P}<0.001$; Figure 4). High heterogeneity $\left(\mathrm{I}^{2}=95 \%\right)$ was found and was not significantly reduced when the analysis was performed using only four RCTs (Lee et al., 2008; Assobhi, 2011; Narsaria et al., 2014; Saha et al., 2014) (MD =-24.72; 95\% CI: -34.40 to -15.04; P < 0.001).

\section{Wound Size}

Six studies reported the size of the surgical wound (Lee et al., 2007; Liu et al., 2010; Assobhi, 2011; Tarng et al., 2012; Fu et al., 2012; Narsaria et al., 2014). The wound size was smaller in the IF group than in the PF group $\left(\mathrm{MD}=-5.07 ; 95 \% \mathrm{CI}:-6.00\right.$ to $-4.13 ; \mathrm{P}<0.001 ; \mathrm{I}^{2}=97 \%$, Figure 5). This result did not significantly change when the result of Liu HH et al. (Liu et al., 2010) was excluded because of a significantly larger wound size (MD $=-4.36 ; 95 \% \mathrm{CI}$ : -5.22 to $3.50 ; \mathrm{P}<0.001)$.

\section{Hospital Stay}

The length of hospital stay was reported in five studies, including 3 RCTs (Lee et al., 2007; Assobhi, 2011; Narsaria et al., 2014) and 2 non-RCTs (Liu et al., 2010; Tarng et al., 2012). Two 
241

242

243

244

245

246

247

248

249

250

251

252

253

254

255

256

257

258

259

260

261

262

263

264

265

266

267

studies (Liu et al., 2010; Assobhi, 2011) provided the original mean and standard deviation, while the other studies published the median and range. The length of hospital stay was shorter in the IF group than in the PF group, regardless of whether the meta-analysis was performed on all of the included studies ( $\mathrm{MD}=-1.31 ; 95 \% \mathrm{CI}:-1.69$ to $-0.93 ; \mathrm{P}<0.001 ; \mathrm{I} 2=80 \%$; Figure 5), on RCTs only ( $\mathrm{MD}=-1.57 ; 95 \% \mathrm{CI}:-2.30$ to $-0.84 ; \mathrm{P}<0.001 ; \mathrm{I} 2=85 \%)$, or on only the studies providing the original mean and standard deviation $(\mathrm{MD}=-0.98 ; 95 \% \mathrm{CI}:-1.36$ to $-0.59 ; \mathrm{P}<$ $0.001)$.

\section{Union Rate and Union Time}

The union rate was reported in all of the included studies. Neither total nor subgroup analysis of RCTs and non-RCTs revealed significant differences between the fixation methods $(\mathrm{OR}=$ 1.41; $95 \% \mathrm{CI}: 0.73$ to $2.75 ; \mathrm{P}=0.31),(\mathrm{OR}=2.20 ; 95 \% \mathrm{CI}: 0.57$ to $7.77 ; \mathrm{P}=0.27)$, and $(\mathrm{OR}=$ 1.23; $95 \%$ CI: 0.56 to 2.66; $\mathrm{P}=0.61$; Figure 7). Union time data were extracted from four RCTs (Lee et al., 2008; Assobhi, 2011; Saha et al., 2014; Narsaria et al., 2014) and two non-RCTs (Liu et al., 2010; Chen et al., 2012). The results based on all of the included studies showed shorter union times in the IF group than in the PF group (MD $=-16.25 ; 95 \% \mathrm{CI}$ : -28.03 to -4.47 ; $\mathrm{P}=$ 0.007; Figure 8). The union time was also shorter in the IF group than in the PF group when the analysis was performed only on RCTs (MD $=-26.40 ; 95 \% \mathrm{CI}:-46.20$ to $-6.61 ; \mathrm{P}=0.009$ ).

\section{Shoulder Score}

Six RCTs (Lee et al., 2007; Lee et al., 2008; Ferran et al., 2010; Assobhi, 2011; Saha et al., 2014; Narsaria et al., 2014) and three non-RCTs (S et al., 2009; Liu et al., 2010; Tarng et al., 2012), including 260 patients in the IF group and 273 patients in the PF group, published the Shoulder score. The meta-analysis based on all included studies did not show superior function in either group $(\mathrm{MD}=1.82 ; 95 \% \mathrm{CI}:-0.05$ to $3.70 ; \mathrm{P}=0.06$; Figure 9$)$; similar results were observed when the analysis included only RCTs $(\mathrm{MD}=1.42 ; 95 \% \mathrm{CI}:-0.68$ to $3.52 ; \mathrm{P}=0.19)$. 
268

269

270

271

272

273

274

275

276

277

278

279

280

281

282

283

284

285

286

287

288

289

290

291

292

293

294

\section{Complications}

All included studies reported on complications related to IF or PF, and more complications occurred in the PF group than in the IF group $(\mathrm{OR}=0.43 ; 95 \% \mathrm{CI}: 0.25$ to $0.76 ; \mathrm{P}=0.003$; Figure 10). When only the major complications (wound infection, nonunion, implant failures, transient brachial plexopathy, and pain after 6 months) were considered, the subgroup analysis also showed more major complications in the PF group than in the IF group $(\mathrm{OR}=0.52 ; 95 \% \mathrm{CI}$ : 0.33 to $0.81 ; \mathrm{P}=0.004)$. No significant differences were found in secondary complications (OR $=0.43 ; 95 \% \mathrm{CI}: 0.16$ to $1.15 ; \mathrm{P}=0.09$ ).

\section{Discussion}

With lower nonunion and malunion rates and better function, especially for displaced fractures, early operative interventions have become the preferred treatment method for mid-shaft clavicular fractures. This meta-analysis reviewed and summarized data from the literature comparing plating fixation and intramedullary fixation. Both surgical techniques showed similar performance in terms of the union rate and shoulder function. With less blood loss, shorter operative time, shorter hospital stay, shorter time to union, and fewer major complications, intramedullary fixation showed better results than plate fixation. Similar results were reported in a meta-analysis of open reduction and internal fixation versus TEN by Duan et al., who observed no significant difference in treatment effects but more side effects in the patients treated with plates (Houwert et al., 2012).

The power of a meta-analysis depends on the quality of the included studies. To provide better evidence for clinical application, we searched and included RCTs and non-RCTs with quality assessment scores ranging from 17 to 20 . For the RCTs, the patients were randomized into two groups using an envelope method in three studies and an alternating one-by-one allocation method in the other studies. The major problem was that not enough information was provided to indicate that participants and treatment providers were blinded to the assignment status. Only two studies described assessor blinding. No prospective calculation of the sample size was 
295

296

297

298

299

300

301

302

303

304

described in the non-RCTs. Moreover, the assessment of the study endpoints was biased. All of these shortcomings weaken the level of evidence.

Compared with open reduction and internal fixation with plates, intramedullary fixation with nails or pins has minimally invasive characteristics, including smaller skin incisions and reduced soft tissue stripping, which are attractive qualities. Therefore, less blood loss, a shorter operative time and a shorter hospital stay definitely benefitted the patients who received intramedullary fixation. Preservation of the soft tissue envelope and periosteum increases the chances of healing (Liu et al., 2010). Stable fixation is another basic principle that can ensure fracture union.

The S-shaped clavicle, as the only bone connecting the upper limb with the body, behaves in a complex manner. Plate fixation is better able to resist the bending and torsional forces exerted during elevation of the upper extremity above shoulder level, thereby potentially providing a stronger construction for early rehabilitation protocols (Golish et al., 2008). Therefore, similar union rates can be realized by either intramedullary fixation or plate fixation because of the sufficient blood supply and stable fixation, as observed in our present review.

Union is the fundamental factor for shoulder function recovery after fractures; for this reason, no significant difference was observed between the union rates of the groups. However, union is not the only factor that can influence clinical function after a clavicular fracture (Lazarides and Zafiropoulos, 2006). The clavicle length plays an important role in maintaining anatomical relationships (McKee et al., 2006). Malunion with more than $15 \mathrm{~mm}$ of shortening has been reported to result in weakness of the glenohumeral extension and abduction (Ledger et al., 2005). Compared with fixation using intramedullary devices, fixation with a contoured plate is the best choice for maintaining the S-shape and length of the clavicle, especially for comminuted fractures. TEN, a newly designed intramedullary device with a curved tip, is flexible and fixed in the cancellous substance of the distal clavicle, and it can better accommodate the S-shaped contour of the clavicle and more tightly adhere to the cortex compared with K-wires, screws, or pins. Surprisingly, clavicle shortening was reported by Chen et al., with 2 cases in the TEN group, and by Wijdicks et al., with 6 cases in the elastic stable intramedullary nail group; 
322

323

324

325

326

327

328

329

330

331

332

333

334

335

336

337

338

339

340

341

342

343

344

345

346

347

348

additionally, Saha et al. reported clavicle shortening by $6.29 \pm 3.75 \mathrm{~mm}$ in the TEN group. We suggest that both plate and intramedullary devices can restore the clavicle to an ideal length to regain most shoulder function. The residual shortening after plate or intramedullary fixation does not significantly influence shoulder function. However, many other factors may also contribute to shoulder function.

As in the study of Assobhi et al. (2011), complications were divided into major complications (including nonunion, infection, implant failure, re-fracture, and transient brachial plexopathy) and secondary complications regarding cosmesis. Extensive soft tissue exposure carries significant risks for nonunion and wound infection in plate fixation. More re-fractures occurred in the plating group because rigid fixation could introduce stress shielding, resulting in bone weakness. Moreover, screw holes may act as focal points for stress, thereby leading to re-fracture. Hardware prominence is the major problem for intramedullary devices. In the literature, the reported rate of hardware prominence ranged from $5.2 \%$ to $38.8 \%$ with the use of an elastic intramedullary nail (Smekal et al., 2009; Jubel et al., 2003; Frigg et al., 2009). Careful surgical manipulation is necessary to avoid prominence. Additionally, cosmetic problems, including hypertrophic scarring and implant prominence, were reported in some studies that showed better results for pin fixation; the lack of such cosmetic problems could be an important factor contributing to the acceptance of this method.

The physiotherapy mentioned in some studies included sling protection for 2 to 4 weeks postoperatively, instructions for gentle and passive range of motion shoulder movements, normal daily activities after a 4-week postoperative period, or weight lifting and the return to full activities after complete fracture healing. Because the activities were similar for both procedures, we trusted that no significant differences exist between the two procedures based on the information we could obtain.

Some limitations should be considered when interpreting these analyses. First, various intramedullary devices and plates were applied in the included studies. Accordingly, we could only report the average performance; thus, more attention must be focused on choosing a specific 
349 pin or nail in clinical practice. The TEN was the most frequently used intramedullary device;

350 more analysis regarding this implant will be necessary in the future. Moreover, classifying some

351 complications as minor may be inappropriate because cosmetic problems are also important

352 issues for female patients. More details of special interest should be considered in the future. As

353 we were limited by unavailable data on the facilities in different cities, we could not analyze the

354 impact of these different facilities on decision making and outcomes. Classifying and comparing

355 outcomes in a chronological order is also difficult to perform. Despite these limitations, we have

356 provided the most comprehensive data comparing plate fixation with intramedullary fixation in

357 the treatment of clavicle fractures.

\section{Conclusion}

359 Based on the results of our meta-analysis, both plate and intramedullary fixation can achieve 360 similar union rates and shoulder function. Considering the better performance of intramedullary

361 fixation in terms of operative parameters and complications, we recommend the application of 362 intramedullary fixation for displaced mid-shift clavicular fractures. More studies focused on 363 comminuted fractures will be necessary in the future.

Funding: No funding was provided to support this study.

Acknowledgement: The authors thank Dr. Zhi-jun Li (Tianjin Medical University General Hospital) and Professor Feng-shi Ma (Department of Mathematics, Tianjin University) for their helping with statistical section of the paper.

\section{Conflict of interest}

All authors declare that they have no conflicts of interest. 
376

377

378

379

380

381

382

383

384

385

386

\section{References}

Ali KM, Lucas HK. 1978. Plating of fractures of the middle third of the clavicle. Injury 9(4):263267.

Assobhi JE. 2011. Reconstruction plate versus minimal invasive retrograde titanium elastic nail fixation for displaced midclavicular fractures. J Orthop Traumatol 12(4):185-192.

Barlow T, Beazley J, Barlow D. 2013. A systematic review of plate versus intramedullary fixation in the treatment of midshaft clavicle fractures. Scott Med J 58(3):163-167.

Bostman O, Manninen M, Pihlajamaki H. 1997. Complications of plate fixation in fresh displaced midclavicular fractures. J Trauma 43(5):778-783.

Chen YF, Wei HF, Zhang C, Zeng BF, Zhang CQ, Xue JF, Xie XT, Lu Y. 2012. Retrospective comparison of titanium elastic nail (TEN) and reconstruction plate repair of displaced midshaft clavicular fractures. J Shoulder Elbow Surg 21(4):495-501.

Duan X, Zhong G, Cen S, Huang F, Xiang Z. 2011. Plating versus intramedullary pin or conservative treatment for midshaft fracture of clavicle: a meta-analysis of randomized controlled trials. J Shoulder Elbow Surg 20(6):1008-1015.

Ferran NA, Hodgson P, Vannet N, Williams R, Evans RO. 2010. Locked intramedullary fixation vs plating for displaced and shortened mid-shaft clavicle fractures: a randomized clinical trial. J Shoulder Elbow Surg 19(6):783-789.

Frigg A, Rillmann P, Perren T, Gerber M, Ryf C. 2009. Intramedullary nailing of clavicular midshaft fractures with the titanium elastic nail: problems and complications. Am J Sports Med 37(2):352-359.

Fu TH, Tan BL, Liu HC, Wang JW. 2012. Anatomical reduction for treatment of displaced midshaft clavicular fractures: Knowles pinning vs. reconstruction plating. Orthopedics 35(1):e23-30.

Golish SR, Oliviero JA, Francke EI, Miller MD. 2008. A biomechanical study of plate versus intramedullary devices for midshaft clavicle fixation. J Orthop Surg Res 3:28.

Handoll HH, Gillespie WJ, Gillespie LD, Madhok R. 2008. The Cochrane Collaboration: a 
403

404

405

406

407

408

409

410

411

412

413

414

415

416

417

418

419

420

421

422

423

424

425

426

427

428

429

leading role in producing reliable evidence to inform healthcare decisions in musculoskeletal trauma and disorders. Indian J Orthop 42(3):247-251.

Higgins JP, Thompson SG, Deeks JJ, Altman DG. 2003. Measuring inconsistency in metaanalyses. BMJ 327(7414):557-560.

Hill JM, McGuire MH, Crosby LA. 1997. Closed treatment of displaced middle-third fractures of the clavicle gives poor results. J Bone Joint Surg Br 79(4):537-539.

Houwert RM, Wijdicks FJ, Steins BC, Verleisdonk EJ, Kruyt M. 2012. Plate fixation versus intramedullary fixation for displaced mid-shaft clavicle fractures: a systematic review. Int Orthop 36(3):579-585.

Hozo SP, Djulbegovic B, Hozo I. 2005. Estimating the mean and variance from the median, range, and the size of a sample. BMC Med Res Methodol 5:13.

Jubel A, Andermahr J, Schiffer G, Tsironis K, Rehm KE. 2003. Elastic stable intramedullary nailing of midclavicular fractures with a titanium nail. Clin Orthop Relat Res 408):279-85.

Kettler M, Schieker M, Braunstein V, Konig M, Mutschler W. 2007. Flexible intramedullary nailing for stabilization of displaced midshaft clavicle fractures: technique and results in 87 patients. Acta Orthop 78(3):424-429.

Kim W, McKee MD. 2008. Management of acute clavicle fractures. Orthop Clin North Am 39(4):491-505.

Lau J, Ioannidis JP, Schmid CH. 1997. Quantitative synthesis in systematic reviews. Ann Intern Med 127(9):820-826.

Lazarides S, Zafiropoulos G. 2006. Conservative treatment of fractures at the middle third of the clavicle: the relevance of shortening and clinical outcome. J Shoulder Elbow Surg 15(2):191194.

Ledger M, Leeks N, Ackland T, Wang A. 2005. Short malunions of the clavicle: an anatomic and functional study. J Shoulder Elbow Surg 14(4):349-354.

Lee YS, Huang HL, Lo TY, Hsieh YF, Huang CR. 2008. Surgical treatment of midclavicular fractures: a prospective comparison of Knowles pinning and plate fixation. Int Orthop 
430

431

432

433

434

435

436

437

438

439

440

441

442

443

444

445

446

447

448

449

450

451

452

453

454

455

456

32(4):541-545.

Lee YS, Lin CC, Huang CR, Chen CN, Liao WY. 2007. Operative treatment of midclavicular fractures in 62 elderly patients: knowles pin versus plate. Orthopedics 30(11):959-64.

Liu HH, Chang CH, Chia WT, Chen CH, Tarng YW, Wong CY. 2010. Comparison of plates versus intramedullary nails for fixation of displaced midshaft clavicular fractures. J Trauma 69(6):E82-87.

Liu PC, Chien SH, Chen JC, Hsieh CH, Chou PH, Lu CC. 2010. Minimally invasive fixation of displaced midclavicular fractures with titanium elastic nails. J Orthop Trauma 24(4):217-223.

McKee MD, Pedersen EM, Jones C, Stephen DJ, Kreder HJ, Schemitsch EH, Wild LM, Potter J. 2006. Deficits following nonoperative treatment of displaced midshaft clavicular fractures. J Bone Joint Surg Am 88(1):35-40.

Meier C, Grueninger P, Platz A. 2006. Elastic stable intramedullary nailing for midclavicular fractures in athletes: indications, technical pitfalls and early results. Acta Orthop Belg 72(3):269-275.

Mueller M, Rangger C, Striepens N, Burger C. 2008. Minimally invasive intramedullary nailing of midshaft clavicular fractures using titanium elastic nails. J Trauma 64(6):1528-1534.

Narsaria N, Singh AK, Arun GR, Seth RR. 2014. Surgical fixation of displaced midshaft clavicle fractures: elastic intramedullary nailing versus precontoured plating. J Orthop Traumatol 15(3):165-171.

Nowak J, Holgersson M, Larsson S. 2004. Can we predict long-term sequelae after fractures of the clavicle based on initial findings? A prospective study with nine to ten years of follow-up. J Shoulder Elbow Surg 13(5):479-486.

O'Neill BJ, Hirpara KM, O'Briain D, McGarr C, Kaar TK. 2011. Clavicle fractures: a comparison of five classification systems and their relationship to treatment outcomes. Int Orthop 35(6):909-914.

Poigenfurst J, Rappold G, Fischer W. 1992. Plating of fresh clavicular fractures: results of 122 operations. Injury 23(4):237-241 
457

458

459

460

461

462

463

464

465

466

467

468

469

470

471

472

473

474

475

476

477

478

479

480

481

482

483

484

485

Postacchini F, Gumina S, De Santis P, Albo F. 2002. Epidemiology of clavicle fractures. J Shoulder Elbow Surg 11(5):452-456.

S TD, Day M, Dent C, Williams R, Evans R. 2009. Treatment of mid-shaft clavicle fractures: A comparative study. Int J Shoulder Surg 3(2):23-27.

Saha P, Datta P, Ayan S, Garg AK, Bandyopadhyay U, Kundu S. 2014. Plate versus titanium elastic nail in treatment of displaced midshaft clavicle fractures: A comparative study. Indian J Orthop 48(6):587-593.

Slim K, Nini E, Forestier D, Kwiatkowski F, Panis Y, Chipponi J. 2003. Methodological index for non-randomized studies (minors): development and validation of a new instrument. ANZ J Surg 73(9):712-716

Smekal V, Irenberger A, Struve P, Wambacher M, Krappinger D, Kralinger FS. 2009. Elastic stable intramedullary nailing versus nonoperative treatment of displaced midshaft clavicular fractures-a randomized, controlled, clinical trial. J Orthop Trauma 23(2):106-112.

Society COT. 2007. Nonoperative treatment compared with plate fixation of displaced midshaft clavicular fractures. A multicenter, randomized clinical trial. J Bone Joint Surg Am 89(1):110.

Tarng YW, Yang SW, Fang YP, Hsu CJ. 2012. Surgical management of uncomplicated midshaft clavicle fractures: a comparison between titanium elastic nails and small reconstruction plates. J Shoulder Elbow Surg 21(6):732-470.

Zhu Y, Tian Y, Dong T, Chen W, Zhang F, Zhang Y. 2015. Management of the mid-shaft clavicle fractures using plate fixation versus intramedullary fixation: an updated meta-analysis. Int Orthop 39(2):319-328.

Zlowodzki M, Zelle BA, Cole PA, Jeray K, McKee MD. 2005. Treatment of acute midshaft clavicle fractures: systematic review of 2144 fractures: on behalf of the Evidence-Based Orthopaedic Trauma Working Group. J Orthop Trauma 19(7):504-507 
486

487

488

489

490

491

492

493

494

495

496

497

498

499

500

501

502

503 504

505

\section{Figure legends}

Figure 1. Flow chart illustrating the identification and selection of cases

Figure 2. Quality assessment of non-randomized trials

Figure 3. Forest plot showing blood loss in the two groups

Figure 4. Forest plot showing the operative time in the two groups

Figure 5. Forest plot showing wound size in the two groups

Figure 6. Forest plot showing the length of hospital stay in the two groups

Figure 7. Forest plot showing the union rate in the two groups

Figure 8. Forest plot showing the union time in the two groups

Figure 9. Forest plot showing the shoulder score in the two groups

Figure 10. Forest plot showing complications in the two groups 


\section{Table $\mathbf{1}$ (on next page)}

Table 1

Characteristics of included studies 
Table 1. Characteristics of included studies

\begin{tabular}{|c|c|c|c|c|c|c|c|c|c|c|}
\hline \multirow{2}{*}{ Study } & \multirow{2}{*}{ Tim } & \multirow{2}{*}{ Type } & \multicolumn{2}{|r|}{ Invention } & \multicolumn{2}{|c|}{ Age(years) } & \multicolumn{2}{|c|}{ Gender(F/M) } & \multicolumn{2}{|c|}{ Follow-up(months) } \\
\hline & & & IF & $\mathrm{PF}$ & IF & $\mathrm{PF}$ & IF & $\mathrm{PF}$ & IF & $\mathrm{PF}$ \\
\hline Lee YS et al. & $\begin{array}{c}200 \\
7\end{array}$ & RCT & Knowles pin & DCP & $60.4(50-81)$ & $56.7(52-79)$ & $\begin{array}{c}32(19 / 1 \\
3)\end{array}$ & $\begin{array}{c}30(17 / 1 \\
3)\end{array}$ & \multicolumn{2}{|c|}{30} \\
\hline Lee YS et al. & $\begin{array}{c}200 \\
8\end{array}$ & $\mathrm{RCT}$ & Knowles pin & $\begin{array}{c}\text { DCP, tubular and reconstruction } \\
\text { plate }\end{array}$ & 40.1 & 38.2 & $\begin{array}{c}56(19 / 3 \\
7)\end{array}$ & $\begin{array}{c}32(12 / 2 \\
0)\end{array}$ & \multicolumn{2}{|c|}{12} \\
\hline Ferran NA et al. & $\begin{array}{c}201 \\
0\end{array}$ & RCT & Rockwood Pin & LC-DCP & $23.8(13-42)$ & $35.4(16-53)$ & $17(14 / 3)$ & $15(13 / 2)$ & $12.7 \pm 3.5$ & $\begin{array}{c}12.1 \pm 5 \\
7\end{array}$ \\
\hline Assobhi JE et al. & $\begin{array}{c}201 \\
1\end{array}$ & $\mathrm{RCT}$ & titanium elastic nail & $3.5 \mathrm{~mm}$ reconstruction plate & $30.3 \pm 4.8$ & $32.6 \pm 5.9$ & $19(16 / 3)$ & $19(17 / 2)$ & $14.5 \pm 1.5$ & $\begin{array}{c}18.6 \pm 3 \\
8\end{array}$ \\
\hline Narsaria $\mathrm{N}$ et al. & $\begin{array}{c}201 \\
4\end{array}$ & $\mathrm{RCT}$ & $\begin{array}{l}\text { titanium elastic } \\
\text { nail }\end{array}$ & $3.5 \mathrm{~mm} \mathrm{DCP}$ & $38.9 \pm 9.1$ & $40.3 \pm 11.2$ & $33(9 / 24)$ & $32(6 / 26)$ & \multicolumn{2}{|c|}{24} \\
\hline Saha $\mathrm{P}$ et al. & $\begin{array}{c}201 \\
4\end{array}$ & $\mathrm{RCT}$ & titanium elastic nail & locking plate & $33.3 \pm 11.8$ & $33.0 \pm 12.6$ & $34(4 / 30)$ & $37(7 / 30)$ & $24.6 \pm 2.4$ & $\begin{array}{c}25.1 \pm \\
3.3\end{array}$ \\
\hline $\begin{array}{c}\text { S, Thyagarajan D } \\
\text { et al. }\end{array}$ & $\begin{array}{c}200 \\
9\end{array}$ & $\begin{array}{c}\mathrm{nRC} \\
\mathrm{T}\end{array}$ & Rockwood Pin & LC-DCP & $28(15-56)$ & $32.1(17-46)$ & $17(1 / 16)$ & $17(2 / 15)$ & \multicolumn{2}{|c|}{$5.9(4-11)$} \\
\hline Liu HH et al. & $\begin{array}{c}201 \\
0\end{array}$ & $\begin{array}{c}\mathrm{nRC} \\
\mathrm{T}\end{array}$ & titanium elastic nail & reconstruction LCP & $33.6 \pm 13.5$ & $31.7 \pm 9.7$ & $\begin{array}{c}51(19 / 3 \\
2)\end{array}$ & $\begin{array}{c}59(30 / 2 \\
9)\end{array}$ & \multicolumn{2}{|c|}{$17.7(12-27)$} \\
\hline Kleweno, CP et al. & $\begin{array}{c}201 \\
1\end{array}$ & $\begin{array}{c}\mathrm{nRC} \\
\mathrm{T}\end{array}$ & Rockwood Pin & $\begin{array}{l}\text { reconstruction plate or locking } \\
\text { plate }\end{array}$ & $35(16-56)$ & $28(16-46)$ & $18(3 / 15)$ & $14(4 / 10)$ & $8(3-28)$ & $17(4-58)$ \\
\hline Fu TH et al. & $\begin{array}{c}201 \\
2\end{array}$ & $\begin{array}{c}\mathrm{nRC} \\
\mathrm{T}\end{array}$ & Knowles pin & reconstruction plate & $35.2 \pm 14.5$ & $39.9 \pm 14.8$ & $\begin{array}{c}53(15 / 3 \\
8)\end{array}$ & $\begin{array}{c}40(17 / 3 \\
3)\end{array}$ & $\begin{array}{c}15(12- \\
153)\end{array}$ & $\begin{array}{c}14(12- \\
92)\end{array}$ \\
\hline Chen, YF et al. & $\begin{array}{c}201 \\
2\end{array}$ & $\begin{array}{c}\mathrm{nRC} \\
\mathrm{T}\end{array}$ & titanium elastic nail & $3.5 \mathrm{~mm}$ reconstruction plates & $\begin{array}{c}38(26.5- \\
58)\end{array}$ & $\begin{array}{c}46.5(36.5- \\
58.8)\end{array}$ & $\begin{array}{c}25(15 / 1 \\
0)\end{array}$ & $\begin{array}{c}32(14 / 1 \\
8)\end{array}$ & & \\
\hline Tarng, YW et al. & $\begin{array}{c}201 \\
2\end{array}$ & $\begin{array}{c}\mathrm{nRC} \\
\mathrm{T}\end{array}$ & titanium elastic nail & reconstruction plates & $34.3(20-59)$ & $36.5(19-63)$ & $\begin{array}{c}57(16 / 4 \\
1)\end{array}$ & $\begin{array}{c}84(23 / 6 \\
1)\end{array}$ & & \\
\hline Wijdicks FJ et al. & 201 & $\mathrm{nRC}$ & titanium elastic nail & reconstruction plate or locking & $39.4 \pm 14.1$ & $33.1 \pm 15.6$ & $43(10 / 3$ & $47(14 / 3$ & $6(5-12)$ & $8(2-15)$ \\
\hline
\end{tabular}




\begin{tabular}{|c|c|c|c|c|c|c|c|c|c|}
\hline & 2 & $\mathrm{~T}$ & & plate & & & 3) & 3) & \\
\hline Wenninger JJ et al. & $\begin{array}{c}201 \\
3\end{array}$ & $\begin{array}{c}\mathrm{nRC} \\
\mathrm{T}\end{array}$ & rigid Hagie pin & $\begin{array}{c}3.5 \mathrm{~mm} \text { reconstruction plate or } \\
\text { LC-DCP }\end{array}$ & $25.2(18-51)$ & $26.9(20-49)$ & $33(1 / 32)$ & $29(3 / 26)$ & 12 \\
\hline Jones, LD et al. & $\begin{array}{c}201 \\
4\end{array}$ & $\begin{array}{c}\mathrm{nRC} \\
\mathrm{T}\end{array}$ & titanium elastic nail & $\mathrm{N}$ & $\mathrm{N}$ & $\mathrm{N}$ & 25 & 24 & $30(12-54)$ \\
\hline
\end{tabular}




\section{Table 2 (on next page)}

Table 2

Quality assessment for randomized trials 
1 Table 2. Quality assessment for randomized trials

\begin{tabular}{|c|c|c|c|c|c|c|}
\hline Quality assessment for randomized trials & $\begin{array}{c}\text { Lee } \\
\text { YS(2007) }\end{array}$ & $\begin{array}{l}\text { Lee } \\
\text { YS }\end{array}$ & $\begin{array}{c}\text { Ferran } \\
\text { NA }\end{array}$ & $\begin{array}{l}\text { Assobhi } \\
\text { JE }\end{array}$ & $\begin{array}{l}\text { Narsaria } \\
\mathrm{N}\end{array}$ & $\begin{array}{c}\text { Saha } \\
\mathrm{P}\end{array}$ \\
\hline Was the assigned treatment adequately concealed prior to allocation? & 1 & 1 & 2 & 2 & 2 & 1 \\
\hline $\begin{array}{l}\text { Were the outcomes of participants who withdrew described and included in the } \\
\text { analysis? }\end{array}$ & 2 & 2 & 2 & 2 & 2 & 2 \\
\hline Were the treatment and control group comparable at entry? & 2 & 2 & 2 & 2 & 2 & 2 \\
\hline Were the outcome assessors blinded to treatment status? & 2 & 0 & 2 & 0 & 0 & 0 \\
\hline Were the participants blind to assignment status after allocation? & 0 & 0 & 0 & 0 & 0 & 0 \\
\hline Were the treatment providers blind to assignment status? & 0 & 0 & 0 & 0 & 0 & 0 \\
\hline Were care programs, other than the trial options, identical? & 2 & 2 & 2 & 2 & 2 & 2 \\
\hline Were the inclusion and exclusion criteria clearly defined? & 2 & 2 & 2 & 2 & 2 & 2 \\
\hline Were the interventions clearly defined? & 2 & 2 & 2 & 2 & 2 & 2 \\
\hline Were the outcome measures used clearly defined? & 2 & 2 & 2 & 2 & 2 & 2 \\
\hline Were diagnostic tests used in outcome assessment clinically useful? & 2 & 2 & 2 & 2 & 2 & 2 \\
\hline Was the surveillance active, and of clinically appropriate duration? & 2 & 2 & 2 & 2 & 2 & 2 \\
\hline
\end{tabular}

2 
1

Figure 1

Flow chart showing identification and selection of cases

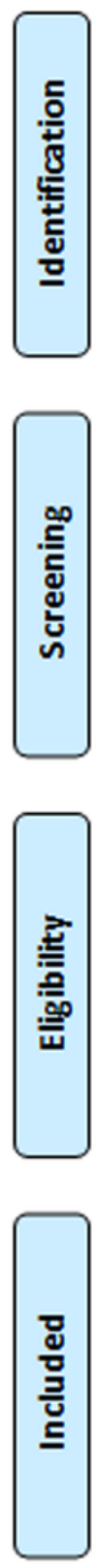

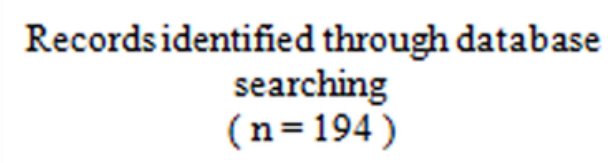

Additional records identified through other sources $(\mathrm{n}=0)$
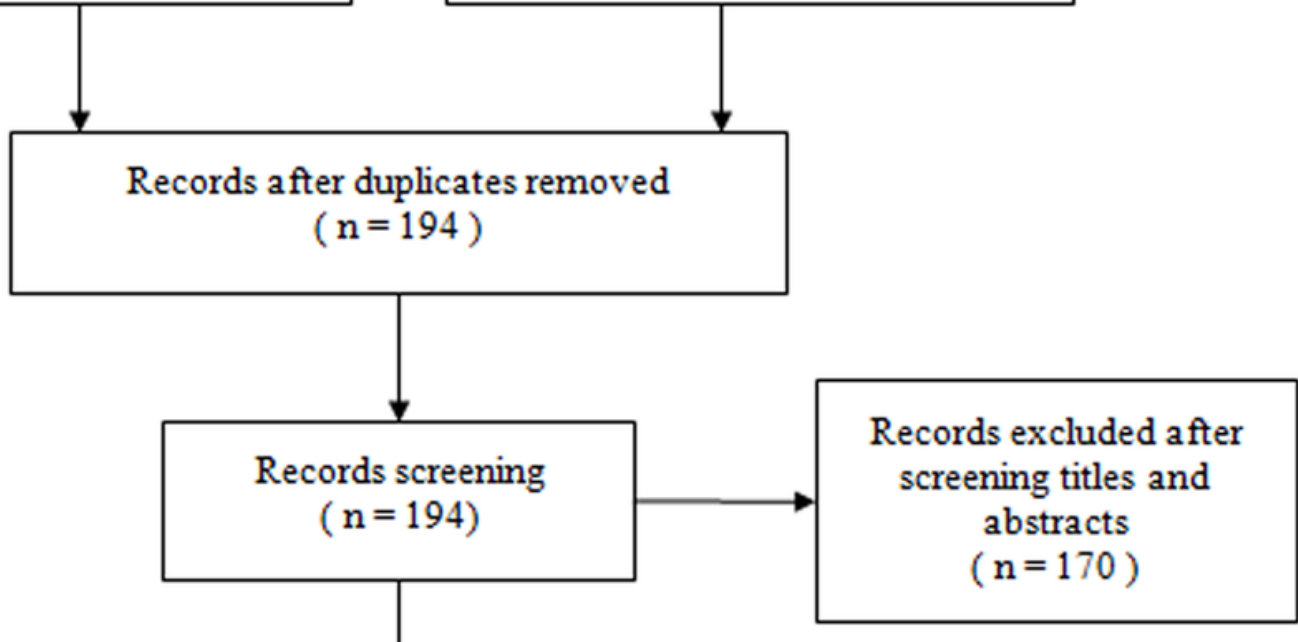

Full-text articles assessed for eligibility $(n=24)$

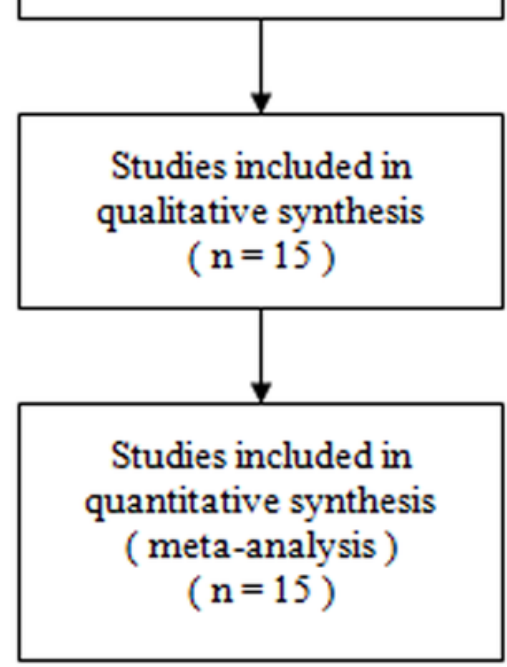

Full-text articles excluded with reasons $(n=9)$ Unclear method description (6) Biomechanical study(1) Insufficient data (2) 
2

Figure 2

Quality assessment for non-randomized trials

\begin{tabular}{|c|c|c|c|c|c|c|c|c|c|c|c|c|}
\hline & 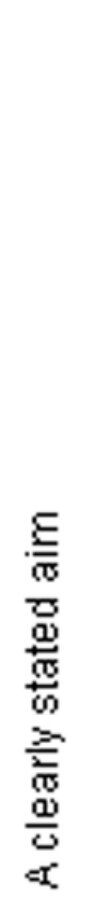 & 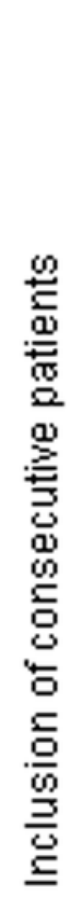 & 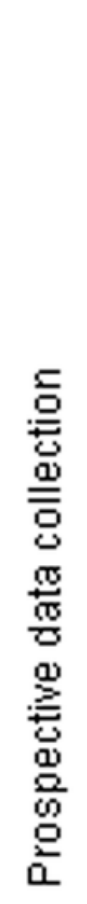 & 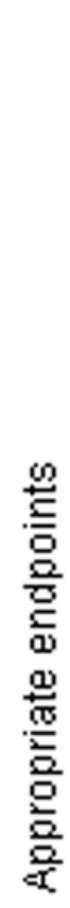 & 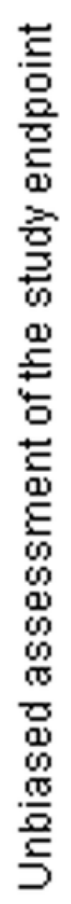 & 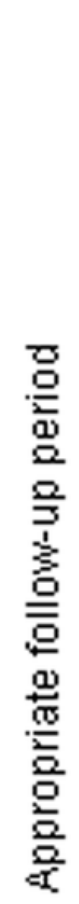 & 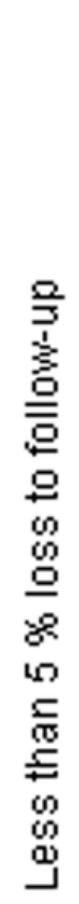 & 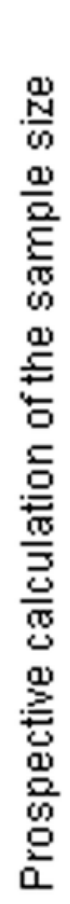 & 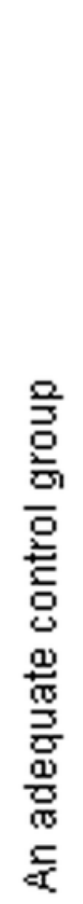 & 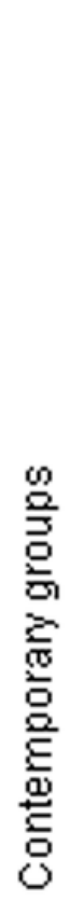 & 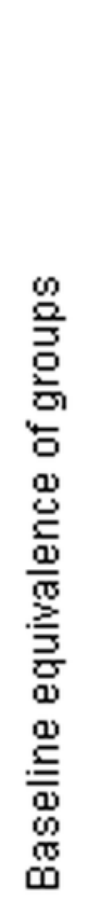 & 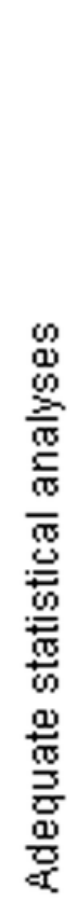 \\
\hline \multicolumn{13}{|l|}{ Chen, YF 2012} \\
\hline \multicolumn{13}{|l|}{ Fu TH 2012} \\
\hline \multicolumn{13}{|l|}{ Jones, LD 2014} \\
\hline \multicolumn{13}{|l|}{ Kleweno, CP 2011} \\
\hline \multicolumn{13}{|l|}{ Liu HH 2010} \\
\hline \multicolumn{13}{|c|}{ S, Thyagarajan D 2009} \\
\hline Tarng, W 2012 & + & + & & + & & + & + & & + & + & $\oplus$ & \\
\hline \multicolumn{13}{|l|}{ Wenninger JJ 2013} \\
\hline Wijdicks FJ 2012 & + & + & & + & & $?$ & + & & + & + & + & + \\
\hline
\end{tabular}


3

Figure 3

Forest plot showing blood loss in the two groups

\begin{tabular}{|c|c|c|c|c|c|c|c|c|c|c|c|c|c|}
\hline \multirow[b]{2}{*}{ Studv or Subgroup } & \multicolumn{3}{|c|}{ IF } & \multicolumn{3}{|c|}{ PF } & \multicolumn{3}{|c|}{ Mean Difference } & \multirow{2}{*}{\multicolumn{4}{|c|}{$\begin{array}{l}\text { Mean Difference } \\
\text { IV, Fixed, } 95 \% \mathrm{Cl}\end{array}$}} \\
\hline & Mean & SD & Total & Mean & SD & Iotal & Weight & IN, Fixed, $95 \% \mathrm{Cl}$ & Year & & & & \\
\hline Liu HH 2010 & 67.4 & 36.7 & 51 & 127.9 & 48.8 & 59 & $2.9 \%$ & $-60.50[-76.52,-44.48]$ & 2010 & & & & \\
\hline Chen, YF 2012 & 65.1 & 26.5 & 57 & 116.3 & 42.3 & 84 & $5.8 \%$ & $-51.20[-62.56,-39.84]$ & 2012 & & & & \\
\hline Tarng, MN 2012 & 12 & 1.25 & 25 & 77.5 & 8.75 & 32 & $79.8 \%$ & $-65.50[-68.57,-62.43]$ & 2012 & & & & \\
\hline Saha P 2014 & 47.7 & 44.7 & 34 & 116.5 & 38.6 & 37 & $2.0 \%$ & $-68.80[-88.30,-49.30]$ & 2014 & & & & \\
\hline Narsaria N 2014 & 70 & 15 & 33 & 130.8 & 21 & 32 & $9.5 \%$ & $-60.80[-69.70,-51.90]$ & 2014 & & & & \\
\hline Total $(95 \% \mathrm{Cl})$ & & & 200 & & & 244 & $100.0 \%$ & $-64.14[-66.88,-61.40]$ & & & $\uparrow$ & & \\
\hline $\begin{array}{l}\text { Heterogeneity: Chi } \\
\text { Test for overall effe }\end{array}$ & $\begin{array}{l}6.69, \mathrm{df} \\
Z=45.8\end{array}$ & $\begin{array}{l}=4(\mathrm{P} \\
3(\mathrm{P}=\end{array}$ & $\begin{array}{l}=0.15) \\
0.0000\end{array}$ & $\begin{array}{l}\left.\right|^{2}=4 \\
1 \text { 1) }\end{array}$ & & & & & & -100 & $\begin{array}{l}-50 \\
\text { Favours IF }\end{array}$ & $\begin{array}{l}50 \\
\text { Favours PF }\end{array}$ & $100^{\circ}$ \\
\hline
\end{tabular}


4

Figure 4

Forest plot showing operative time in the two groups

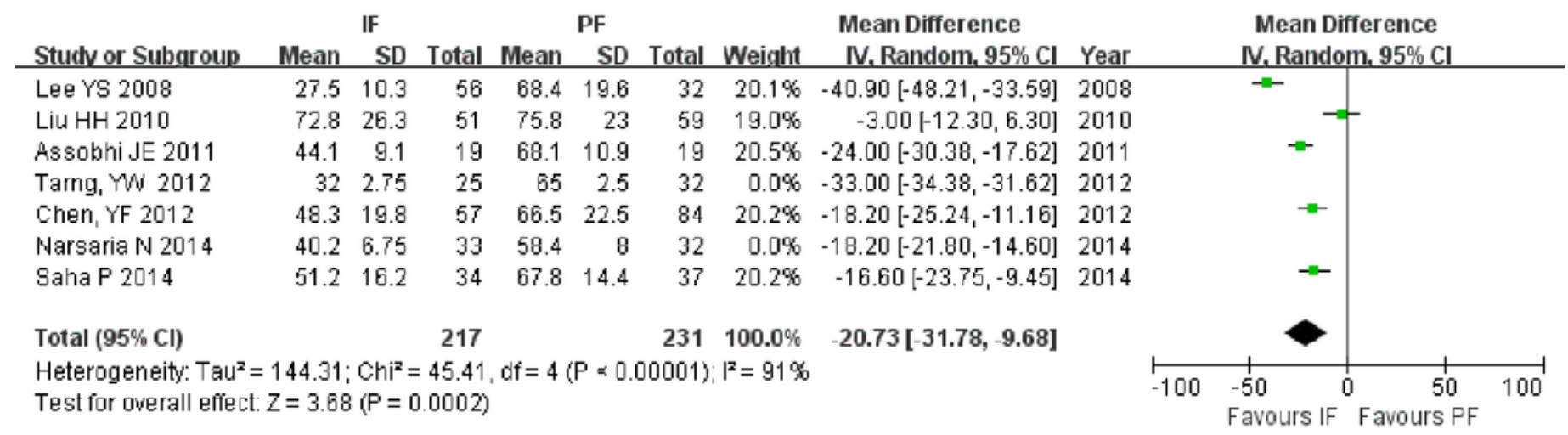




\section{5}

Figure 5

Forest plot showing wound size in the two groups

\begin{tabular}{|c|c|c|c|c|c|c|c|c|c|c|c|c|c|}
\hline Stuctv or Subgroup & Mean & $\begin{array}{l}\text { IF } \\
\text { SD }\end{array}$ & Total & Mean & $\begin{array}{l}\text { PF } \\
\text { SD }\end{array}$ & Total & Weight & $\begin{array}{l}\text { Mean Difference } \\
\text { IV, Random, } 95 \% \mathrm{Cl}\end{array}$ & Year & \multicolumn{4}{|c|}{$\begin{array}{c}\text { Mean Difference } \\
\text { IV. Random, 95\% Cl }\end{array}$} \\
\hline Lee YS 2008 & 4.1 & 0.3 & 56 & 8.4 & 1.6 & 32 & $17.4 \%$ & $-4.30[-4.86,-3.74]$ & 2008 & & $=$ & & \\
\hline Liu HH 2010 & 11.9 & 4.4 & 51 & 22.3 & 4.5 & 59 & $11.7 \%$ & $-10.40[-12.07,-8.73]$ & 2010 & $\leftarrow$ & & & \\
\hline Assobhi JE 2011 & 4.3 & 0.8 & 19 & 8.5 & 1.6 & 19 & $16.3 \%$ & $-4.20[-5.00,-3.40]$ & 2011 & & $\rightarrow$ & & \\
\hline Tarng, WW 2012 & 3 & 0.3 & 25 & 7.5 & 0.3 & 32 & $18.4 \%$ & $-4.50[-4.66,-4.34]$ & 2012 & & - & & \\
\hline Fu TH 2012 & 5.3 & 0.9 & 53 & 8.4 & 0.5 & 50 & $18.2 \%$ & $-3.10[-3.38,-2.82]$ & 2012 & & $=$ & & \\
\hline Narsaria N 2014 & 4.5 & 0.6 & 33 & 10.2 & 0.9 & 32 & $18.0 \%$ & $-5.70[-6.07,-5.33]$ & 2014 & & $=$ & & \\
\hline Total $(95 \% \mathrm{Cl})$ & & & 237 & & & 224 & $100.0 \%$ & $-5.07[-6.00,-4.13]$ & & & & & \\
\hline $\begin{array}{l}\text { Heterogeneity. Tau } \\
\text { Test for overall effect }\end{array}$ & $\begin{array}{l}1.24 ; \mathrm{Cl} \\
I=10.5\end{array}$ & $\begin{array}{l}h i^{2}= \\
9(P\end{array}$ & $\begin{array}{l}181.52 \\
=0.000\end{array}$ & $\begin{array}{l}d f=5(1) \\
01)\end{array}$ & $P \approx 0$ & .00001 & ); $\left.\right|^{2}=97 x$ & & & -10 & $\begin{array}{l}-5 \\
\text { Favours }\end{array}$ & $\begin{array}{rr}0 & 5 \\
& \text { Favours } P\end{array}$ & 10 \\
\hline
\end{tabular}




\section{6}

Figure 6

\section{Forest plot showing hospital stays in the two groups}

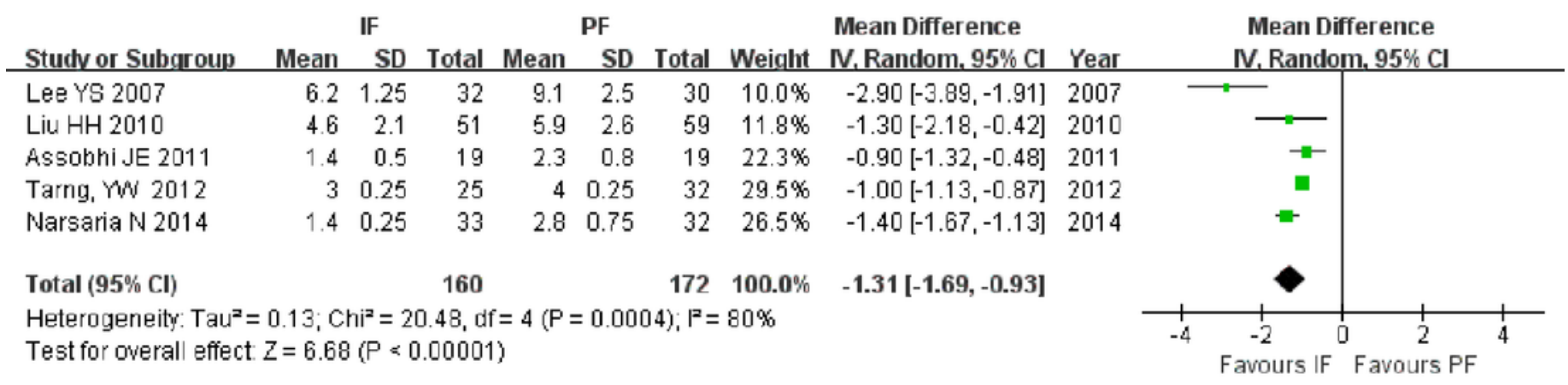




\section{7}

\section{Figure 7}

Forest plot showing union rate in the two groups

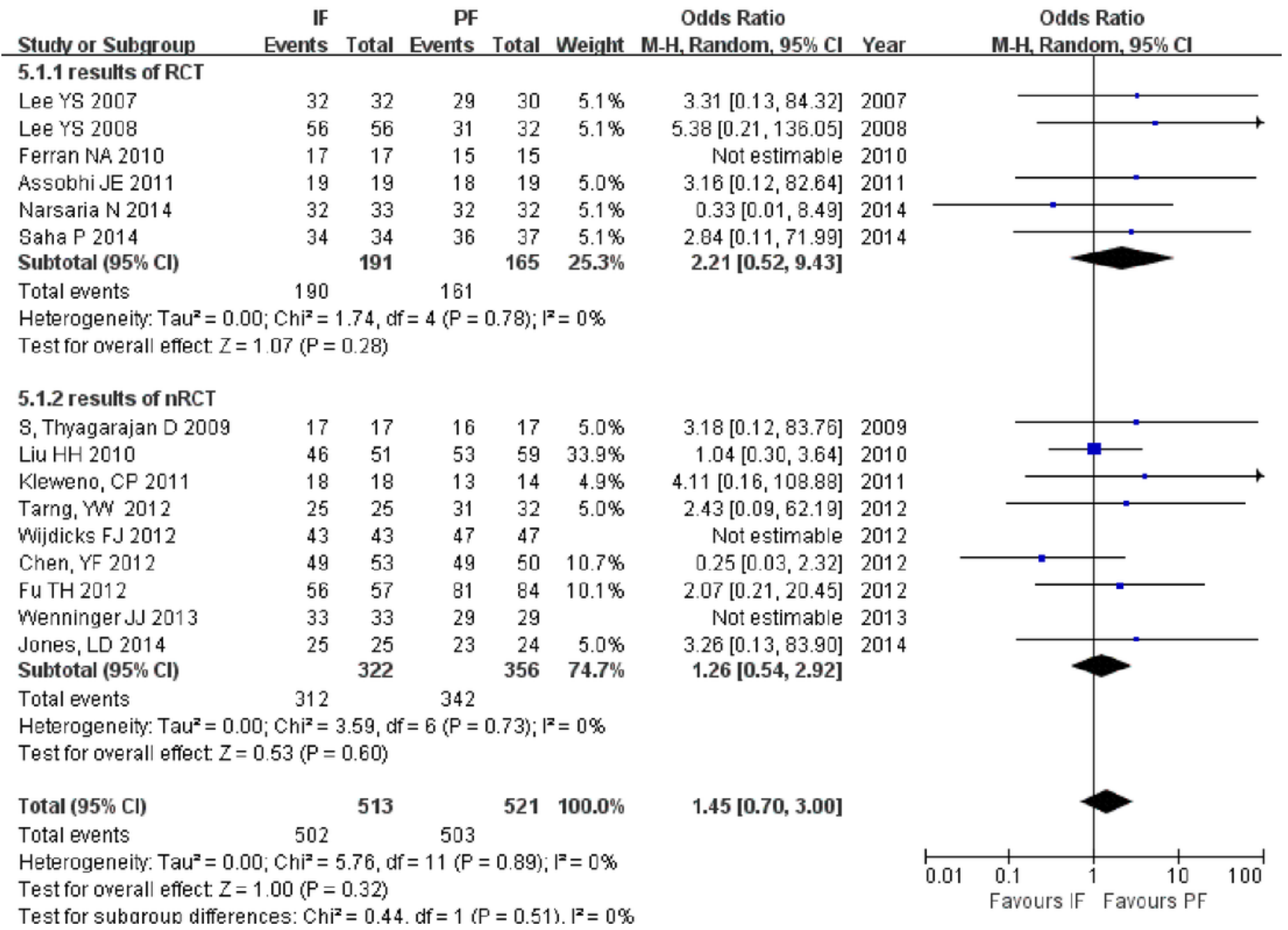


8

Figure 8

Forest plot showing union time in the two groups

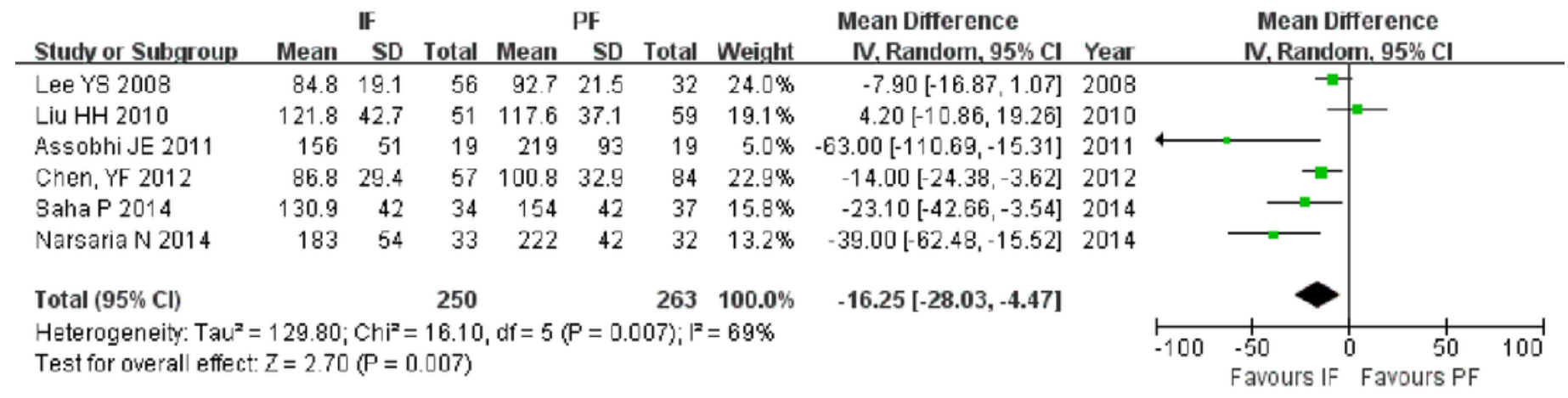


9

Figure 9

Forest plot showing shoulder score in the two groups

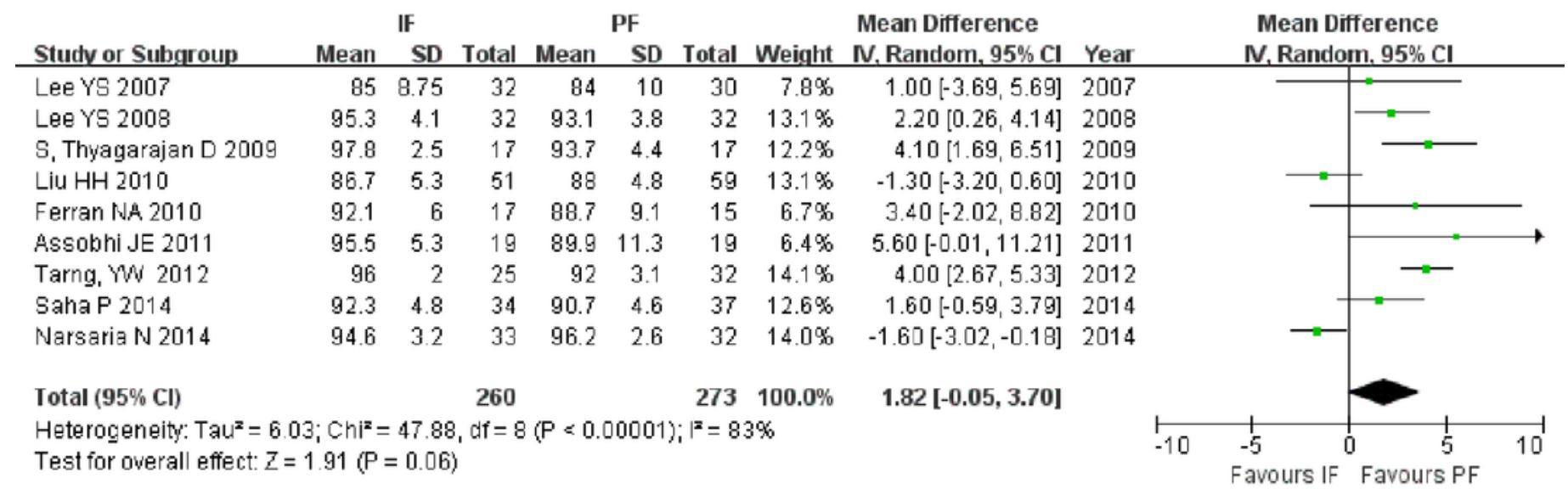


Figure 10

Forest plot showing complications in the two groups

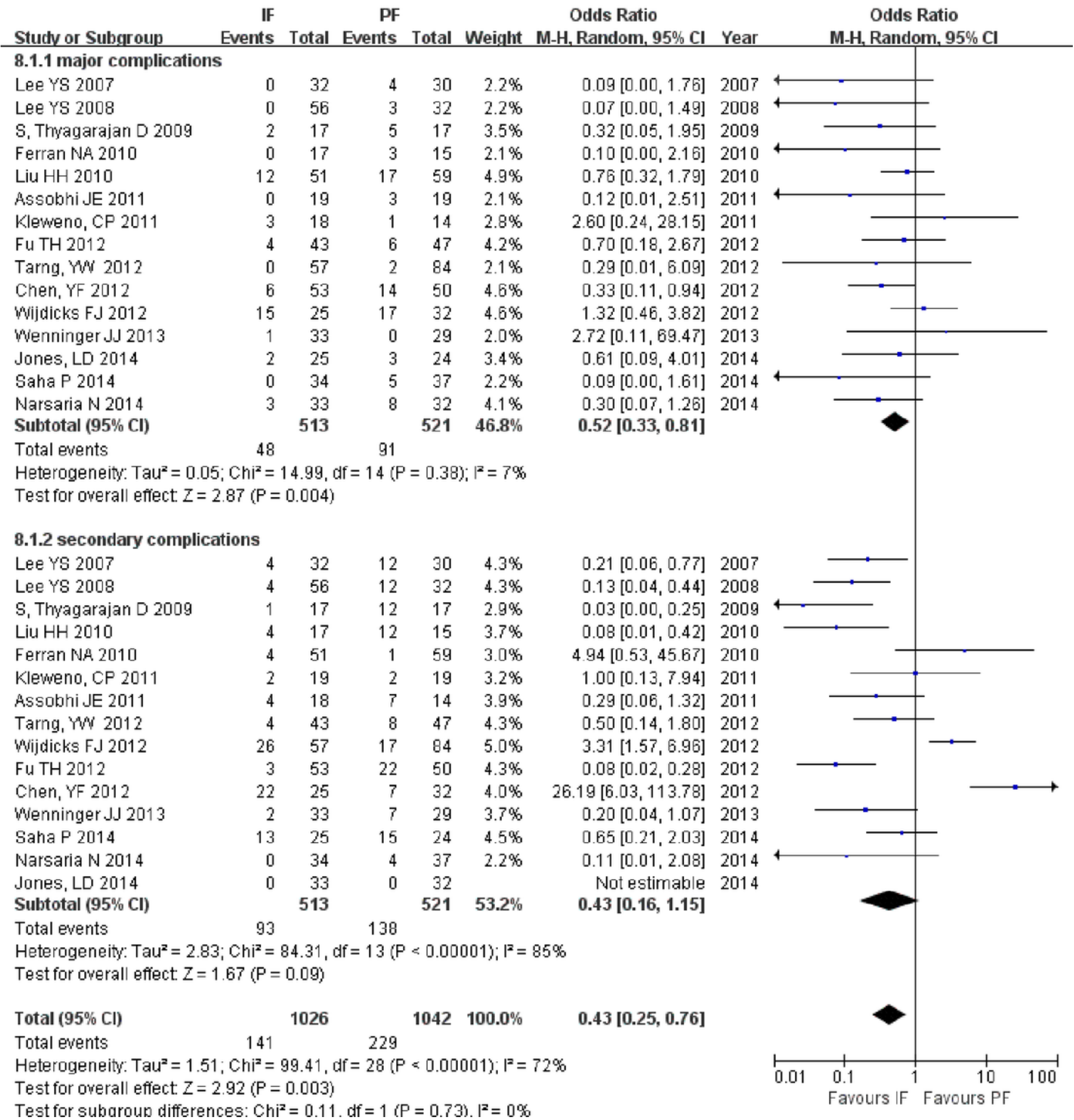

